\title{
Eye Drops, Prolonged-Release Solution in Single-dose Container
}

National Cancer Institute

\section{Source}

National Cancer Institute. Eye Drops, Prolonged-Release Solution in Single-dose

Container. NCI Thesaurus. Code C149505.

Medicinal product consisting of a prolonged-release eye drops solution presented in a single-dose container. 